\title{
Does body height reduction influence interpretation of lung function in COPD patients?
}

\author{
A. Kjensli*, M. Ryg*, J.A. Falch", G. Armbrecht", L.M. Diep ${ }^{+}$, \\ E.F. Eriksen ${ }^{\#}$ and I. Ellingsen*
}

ABSTRACT: Vertebral deformities are prevalent in chronic obstructive pulmonary disease (COPD) patients and may cause excessive loss of height. As height is used for calculating reference values for pulmonary function tests, larger than normal height reduction could cause overestimation of lung function.

In this cross-sectional study of 465 COPD patients and 462 controls, we explored how often lung function is misinterpreted due to height reduction in COPD patients, and whether the number or severity of vertebral deformities correlate with height reduction.

Measured height was compared to recalled tallest height (RTH) and height calculated from arm span (ASH) to assess height reduction. Vertebral deformities were assessed from radiographs and pulmonary function was assessed using standard formulae.

Height reduction was frequent in both the study and control groups, and increased with the number and severity of vertebral deformities. When using current measured height, lung function was overestimated in a significant proportion of COPD patients at relatively modest height reductions. The effects were smallest for forced expiratory volume in $1 \mathrm{~s}$ and forced vital capacity, and most pronounced for total lung capacity and residual volume. Therefore, we propose that in COPD patients with excessive height reduction, one might use RTH or ASH in calculating predicted values. Furthermore, such patients should be evaluated for co-existing vertebral deformities and osteoporosis.

KEYWORDS: Chronic obstructive pulmonary disease, height reduction, lung function, pulmonary function test, spinal deformity index, vertebral deformities

I n Caucasians, height reduction of $\sim 1 \mathrm{~cm}$ per decade occurs during the age of 40-50 yrs and accelerates after $60 \mathrm{yrs}$ of age in both sexes, but to a greater extent in females. Age accounts for $\geqslant 86 \%$ of the variation in the rate of height reduction [1]. The height reduction is multifactorial (e.g. vertebral deformities, changes in the cartilaginous intervertebral discs, loss of muscle tone and postural slump). An association between height reduction and vertebral deformities has been described in the general European population [2] as well as in post-menopausal females with osteoporosis [3].

As lung function measurements are presented as a percentage of predicted values, which depend on age, sex and height [4], height reduction may influence evaluation of lung function tests. Vertebral deformities are prevalent in chronic obstructive pulmonary disease (COPD) patients [5], and may lead to height reduction beyond what is normally expected with age. In such patients, predicted values will be underestimated and, thus, lung function overestimated. It is not known, however, how much the deformities influence height and, thus, the predicted values of lung function tests in these patients.

Both between and within countries there are different practices by which height is used for calculating predicted values. Some centres use current measured height $(\mathrm{CMH})[6]$, while others use self-reported height, recalled tallest height (RTH) [7] or arm span [8]. These measurements will all result in different estimates of lung function, and consequently affect the intervention offered to these patients. Current recommendations for lung function testing include protocols for measuring height and arm span for patients with deformities of the thoracic cage [9].

In this cross-sectional case-control study, the primary objective was to explore the extent of

\section{AFFILIATIONS}

*Glittreklinikken, Hakadal,

${ }^{\#}$ Clinic of Endocrinology, Aker University Hospital and Faculty of Medicine, University of Oslo, and ${ }^{+}$Dept of Research, Aker University Hospital, Oslo, Norway

"Centre for Muscle and Bone Research, Dept of Radiology, Charité - Universitätsmedizin, Berlin, Germany.

CORRESPONDENCE

A. Kjensli

Glittreklinikken

Pb 104 Aaneby

N-1485 Hakadal

Norway

E-mail: aina.kjensli@

glittreklinikken.no

Received:

Sept 212009

Accepted after revision:

Jan 082010

First published online:

Jan 282010 
height reduction and its effect on interpretation of lung function indices in COPD patients.

The secondary objective was to explore whether the number and severity of vertebral deformities correlated with height reduction.

\section{MATERIALS AND METHODS}

Our study is part of a larger study on the consequences of vertebral deformities for lung function. Based on a pilot study, the number needed to demonstrate a $12 \%$ difference in forced expiratory volume in $1 \mathrm{~s}$ (FEV1) between patients with and without vertebral deformities was 462 COPD patients of both sexes at a significance level of 0.05 and a power of 0.80 [5].

\section{Subjects}

From September 2005 to October 2007, 1,004 consecutively admitted COPD patients attending a rehabilitation programme at Glittreklinikken, Hakadal, Norway were evaluated for inclusion. Of these, 492 either had to be excluded or did not meet the inclusion criteria. Of the remaining 512, 47 dropped out, resulting in a study group of 465 COPD patients.

Inclusion and exclusion criteria were as previously described [5].

Written informed consent was obtained from all subjects. The study was approved by the regional committee for medical research ethics.

\section{Control group}

The control group consisted of 462 individuals randomly selected from the Oslo study group in the European Vertebral Osteoporosis Study (EVOS), which consisted of 587 individuals from the general population, aged between 50 and $80 \mathrm{yrs}$ [10]. The prevalence of COPD in this population is not reported, and EVOS did not include lung function tests.

\section{Measurements}

Pulmonary function tests (PFTs) were carried out by trained operators in accordance with American Thoracic Society (ATS)/ European Respiratory Society (ERS) guidelines [11] using Master screen equipment (Jaeger GmbH, Würtzburg, Germany). Reference values were based on equations from the European Community for Steel and Coal (ECSC) [4], or where available, post-bronchodilatory values from JOHANNESSEN et al. [12], according to recommendations from the ATS/ERS [13] and the Global Initiative for Chronic Obstructive Lung Disease [14]. PFTs were repeated within 4 days, and the highest post-bronchodilator measurements were registered.

Height and weight were measured with the patients wearing light indoor clothing and without shoes, and body mass index was calculated $\left(\mathrm{kg} \cdot \mathrm{m}^{-2}\right)$. The height was measured with a wallmounted stadiometer while the subject was standing as tall as possible with the buttocks, back and head against the wall and looking straight ahead [9]. Height measurements in this study (to the nearest $0.5 \mathrm{~cm}$ ) were performed between 09:00 h and $11.30 \mathrm{~h}$, repeated within 4 days, and the mean value recorded. Height measurements in EVOS were performed in the afternoon.

The patients were asked about their RTH (nearest $1.0 \mathrm{~cm}$ ) before the height measurements. If $\mathrm{RTH}$ was reported as $>2 \mathrm{~cm}$ lower than their CMH, RTH was recorded as "could not be recalled" and the patient was excluded from further analysis.

Arm span (distance between the tips of the middle fingers of maximally extended horizontal arms) was measured twice within 4 days on the standing subjects according to LINDERHOLM and LINDGREN [15]. Arm span height (ASH; body height estimated from arm span) was calculated by algorithms from LINDERHOLM and LINDGREN [15] (ASHLinderholm) and PARKER et al. [16] (ASHParker).

Thoracic and lumbar spine radiographs were taken with the patient lying in the left lateral position [10]. A special breathing technique was used that allowed blurring of overlying ribs and lung details by motion. The film was centred at Th7 and L2. All radiographs were evaluated at the Center for Muscle and Bone Research (Benjamin Franklin Hospital, Berlin, Germany).

Vertebral deformities were assessed using a semi-quantitative (SQ) approach [17]. For each vertebra anterior (a), mid (m), and posterior $(\mathrm{p})$, heights and corresponding height ratios $(\mathrm{a} / \mathrm{p}, \mathrm{m} /$ $\left.\mathrm{p}, \mathrm{p} / \mathrm{p}_{\text {up }}, \mathrm{p} / \mathrm{p}_{\text {low }}\right)$ were estimated. Height $\mathrm{p}_{\text {up }}$ and $\mathrm{p}_{\text {low }}$ are the posterior heights of the vertebrae one level above and one below the assessed vertebra. A vertebra was considered to have a deformity if any height ratio at baseline was $<0.80$ [18]. The severity of deformities was graded in SQ grades where grade 0 is normal, grade 1 has a height ratio of $0.80-0.60$, grade 2 a ratio of $0.60-0.40$, and grade 3 a ratio $<0.40$. To characterise the total burden of the vertebral deformities, both the number and the severity of the vertebral deformities were incorporated into a single measure; the spinal deformity index (SDI). SDI is calculated by summing the SQ grades of all vertebrae from Th4 to L4 [17].

As Glittreklinikken changed radiography equipment during the study, 255 of the radiographs were obtained with a Diagnost 88 (Philips, Paris, France) and the remainder with a ddRFormula Plus (Swissray, Hochdorf, Switzerland).

\section{Statistics}

The agreement between different methods of height measures was assessed by a Pearson correlation coefficient with $95 \%$ confidence interval for precision measures of height and average bias [19]. The bias was tested by a paired t-test, and depicted by a Bland-Altman plot. Chi-squared tests were used for testing differences in distributions of categorical variables. Two sample t-tests were used to assess difference in height reduction categories between sexes, and between study and control groups. The impacts of height reduction categories, sex and group variable on SDI, and interactions between them, were assessed by a two-way ANOVA. The analyses were performed using SPSS 16.0 for Windows (SPSS Inc., Chicago, IL, USA). We regarded results as clinically significant if PFTs, as \% of predicted, based on CMH versus RTH or ASHParker, differed by $>5 \%$-points.

\section{RESULTS}

There were no significant differences between the study and the control groups regarding sex or height (table 1). There was a significantly lower age and higher number of subjects with vertebral deformities and number of vertebral deformities per subject in the study than in the control group. There were no data on lung function in the control group. 


\begin{tabular}{|c|c|c|c|}
\hline \multirow[t]{2}{*}{ TABLE 1} & \multirow[b]{2}{*}{ Study group } & \multirow[b]{2}{*}{ Control group } & \multirow[b]{2}{*}{$\mathrm{p}$-value } \\
\hline & & & \\
\hline Males/females $n$ & $223 / 230$ & $213 / 212$ & 0.792 \\
\hline \multirow{2}{*}{$\begin{array}{l}\text { Age yrs } \\
\text { Subjects with vertebral } \\
\text { deformities }^{\#}\end{array}$} & 63 (32-83) & $65(50-80)$ & 0.001 \\
\hline & $136(30)$ & $89(21)$ & 0.002 \\
\hline $\begin{array}{l}\text { Vertebral deformities } \\
\text { per subject }\end{array}$ & $0.8(0-13)$ & $0.5(0-11)$ & 0.001 \\
\hline Height $\mathrm{cm}$ & 169 (146-193) & $169(142-196)$ & 0.866 \\
\hline FEV1 L & $1.3(0.4-3.0)$ & & \\
\hline FVC L & $2.8(1.1-6.1)$ & & \\
\hline TLC L & $7.6(3.2-13.2)$ & & \\
\hline RV L & $4.6(1.8-9.7)$ & & \\
\hline
\end{tabular}

Data are presented a mean (range) or $\mathrm{n}(\%)$, unless otherwise stated. FEV1: post-bronchodilator forced expiratory volume in $1 \mathrm{~s}$; FVC: post-bronchodilator forced vital capacity; TLC: total lung capacity; RV: residual volume. ${ }^{\#}$ : vertebral deformities with semi-quantitative grade $>0$

\section{Variation in height measurements}

There was a between-days variation $>0.5 \mathrm{~cm} \mathrm{CMH}$ in $57 \%$ of the study group, and the measurements varied up to $\pm 3 \mathrm{~cm}$. $95 \%$ of the $\mathrm{CMH}$ measurement differences were within $\pm 1 \mathrm{~cm}$ (fig. 1). The first and second $\mathrm{CMH}$ and arm span measurements were highly correlated $(r=0.998$ and $r=0.997$, respectively). On average, the second $\mathrm{CMH}$ and arm span measurements were slightly lower than the first (mean \pm SD difference $-0.13 \pm$ $0.60 \mathrm{~cm}, \mathrm{p}<0.0001$ and $-0.11 \pm 0.87 \mathrm{~cm}, \mathrm{p}=0.008$, respectively). $85 \%$ of the differences in arm span measurements were within $\pm 1 \mathrm{~cm}$. Between-days variation in $\mathrm{CMH}$ and arm span measurement was not significantly different $(p=0.665)$.

\section{Extent of height reduction}

The between-days variations in $\mathrm{CMH}$ were $<2 \mathrm{~cm}( \pm 1 \mathrm{~cm})$ in $95 \%$ of our study population. We therefore regarded a height difference between RTH or ASHParker and CMH of $>2 \mathrm{~cm}$ as a true loss of height. A height reduction of $>2 \mathrm{~cm}$ was found in $55 \%$ of the study group and $61 \%$ of the control group using $\mathrm{RTH}$ as baseline, and $56 \%$ of the study group using ASHParker as baseline.

$\mathrm{CMH}$ was significantly correlated with $\mathrm{RTH}(\mathrm{r}=0.966,95 \% \mathrm{CI}$ 0.959-0.972), ASHLinderholm ( $\mathrm{r}=0.919,95 \%$ CI $0.904-0.932)$ and ASHParker $(\mathrm{r}=0.938,95 \%$ CI $0.926-0.948)$. On average, RTH was $2.3 \pm 2.4 \mathrm{~cm}$ higher than $\mathrm{CMH}(\mathrm{p}<0.0001)$, ASHLinderholm was $2.4 \pm 3.8 \mathrm{~cm}$ lower than $\mathrm{CMH}(\mathrm{p}<0.0001)$, and ASHParker was $2.5 \pm 2.8 \mathrm{~cm}$ higher than $\mathrm{CMH}(\mathrm{p}<0.0001)$. Since an average increase in height after age 25 yrs is highly unlikely, we excluded ASHLinderholm from further analysis. RTH and ASHParker were not significantly different $(\mathrm{p}=0.76)$.

$\mathrm{RTH}$ could not be recalled or were considered wrong (CMH $\mathrm{RTH}>2 \mathrm{~cm}$ ) in 12 subjects in the study group and 37 controls. These subjects were excluded from further analysis involving RTH. Similarly, CMH - ASHParker was $>2 \mathrm{~cm}$ in 71 subjects. These were excluded from analysis involving ASHParker. There were no differences in sex, age or height with respect to missing data on RTH or ASHParker.

Since $95 \%$ of the duplicate measurements were within $2 \mathrm{~cm}$ of each other, we divided the height reduction from RTH and ASHParker to $\mathrm{CMH}$ into categories of 2-cm intervals. There was no significant difference in the height reduction categories between males and females in either RTH or ASHParker (fig. 2).

The study group had, on average, $0.2 \mathrm{~cm}$ larger RTH-based height reduction than the controls $(p=0.010)$. There was no significant sex difference in the height reduction categories between the study and control group $(p=0.154)$.

In the study group there was a significant positive correlation between height reduction and height expressed as $(\mathrm{CMH}+$ $\mathrm{RTH}) / 2(\mathrm{r}=0.17 ; \mathrm{p}<0.0001)$ and age $(\mathrm{r}=0.35 ; \mathrm{p}<0.0001)$. The regression coefficients for height and age were 0.04 and 0.1 , respectively. This means that a subject with a height of, for example, $150 \mathrm{~cm}$ has a height reduction of $1 \mathrm{~cm}$ less than a subject with a height of $175 \mathrm{~cm}$, and that height reduction increases with $1 \mathrm{~cm}$ per decade of age. The same trends were

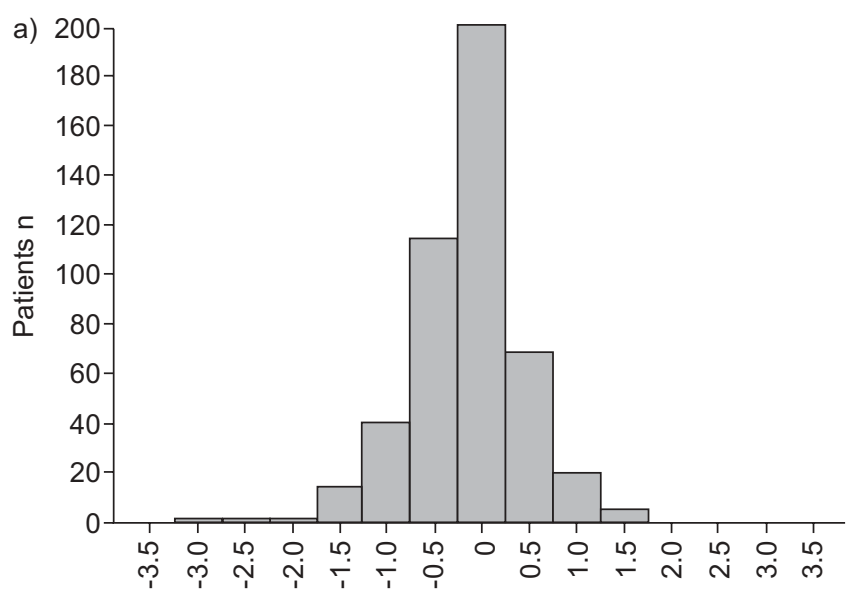

Between-days variation b)

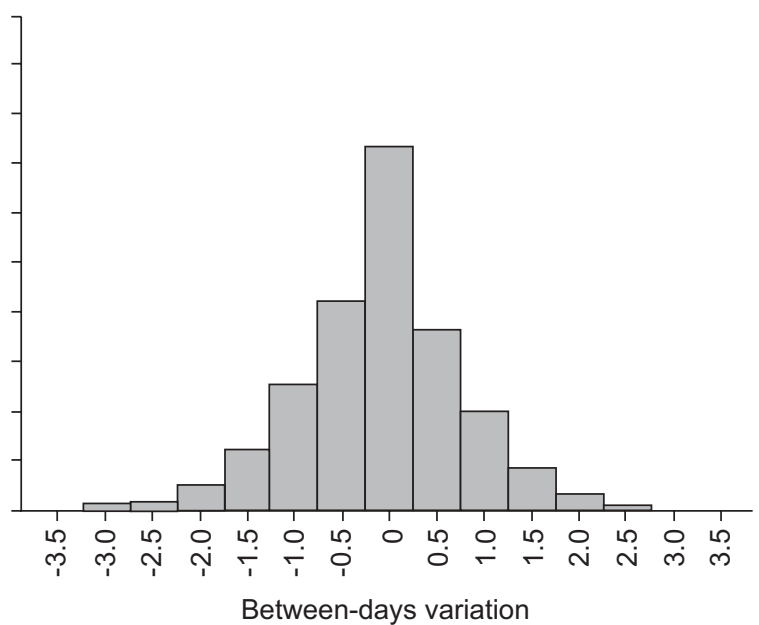

FIGURE 1. Between-days variation in a) current measured height (mean $\pm S D-0.131 \pm 0.6026 \mathrm{~cm}, \mathrm{n}=465)$ and $\mathrm{b})$ arm span $(-0.108 \pm 0.8699 \mathrm{~cm}, \mathrm{n}=463)$. 

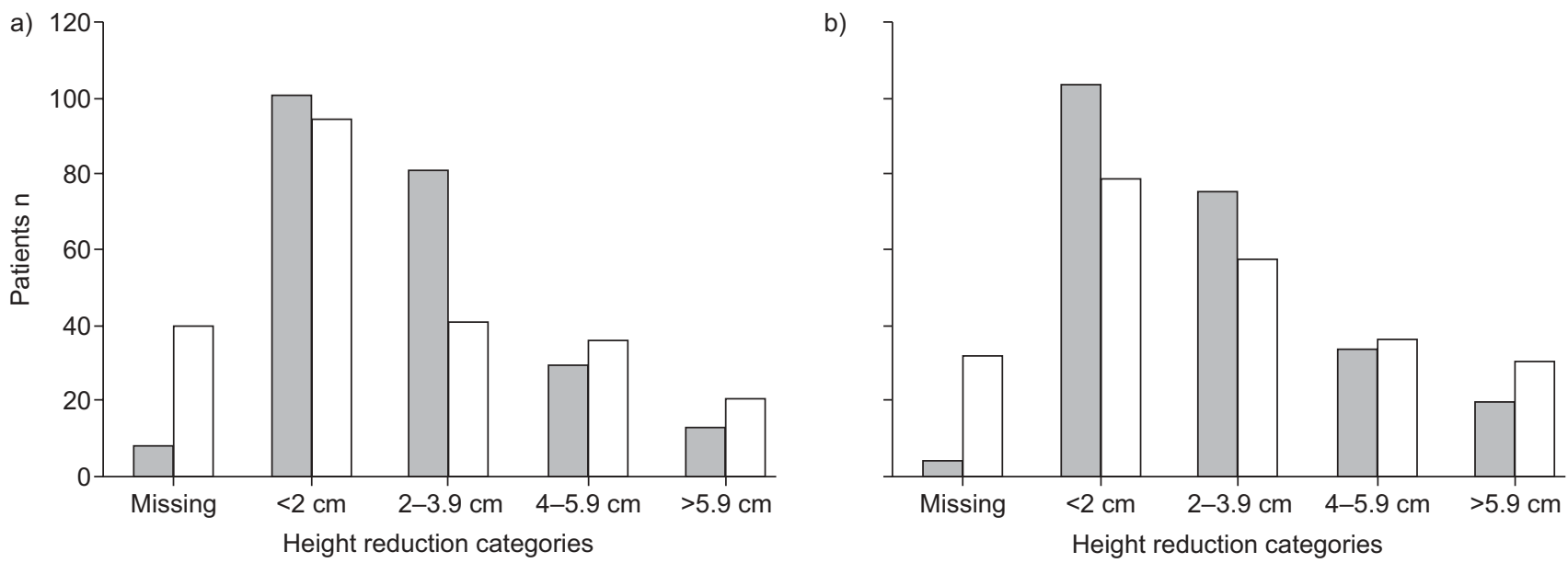

FIGURE 2. Height reduction from recalled tallest height to current measured height ( $\square$ ) and arm span height to current measured height ( $\square$ ) in a) males and b) females in the study group.

evident in the control group and, if height was expressed as $\left(\mathrm{CMH}+\mathrm{ASH}_{\text {Parker }}\right) / 2$, in the study group (data not shown).

\section{Effect of height reduction on interpretation of lung function}

The percentage-point difference in PFTs increased with increasing height reduction irrespective of whether RTH or ASH was used as the basis (fig. 3). The effect of height reduction was less for FEV1 and FVC than for TLC and RV.

As stated in the statistics section we regarded a difference of 5\%-points for PFT as clinically significant. Using the predictions of JOHANNESSEN et al. [12] for FEV1 and FVC, and the ECSC predictions for TLC and RV, the proportion of COPD patients where the PFT differences exceeded 5\%-points increased with increasing height reduction. The effects were somewhat larger when ASHParker was used as basis for calculating height reduction (table 2). In a significant fraction of the males, the difference in FEV1 exceeded 5\%-points for a height reduction $\geqslant 6 \mathrm{~cm}$, for FVC $\geqslant 4 \mathrm{~cm}$, and for TLC and RV $\geqslant 2 \mathrm{~cm}$. In females, the differences exceeded 5\%-points with height reduction $\geqslant 4 \mathrm{~cm}$ for $\mathrm{FEV} 1$, and in all height reduction categories for FVC, TLC and RV. Using the ECSC instead of the predictions of JOHANNESSEN et al. [12] for FEV1 and FVC resulted in smaller fractions of males and larger fractions of females with differences exceeding 5\%-points.

There were no significant differences in pulmonary function between subjects with $0,1-2$ or $>2$ vertebral deformities (table 3 ). The same was found when analysing females and males separately (data not shown).

\section{Height reduction compared to number and severity of vertebral deformities}

The proportion of subjects with deformities increased with increasing RTH-based height reduction both in the study group $(\mathrm{r}=0.43)$ and the control group $(\mathrm{r}=0.34, \mathrm{p}<0.0001$ for both) (table 4 ). Within height reduction categories, the study group had a significantly higher fraction of subjects with vertebral deformities $(p<0.0001)$, a higher number of vertebral deformities $(p=0.003)$ and higher SDI $(p<0.0001)$ (table 4, fig. 4).
SDI increased with increasing height reduction in both study $(p<0.0001)$ and control groups $(p<0.0001)$. The interaction effect between sex and height reduction on SDI was not statistically significant in either group, and the results are therefore presented for both sexes. SDI increased with increasing height reduction and, also when only subjects with vertebral deformities were considered. The differences in SDI between the study and control groups were, however, only borderline significant $(\mathrm{p}=0.052)$.

Figure 4 also shows that the mean height reduction in every height reduction category was slightly greater in the study than the control group.

\section{DISCUSSION}

In this study we have shown that patients with COPD exhibit a reduction in body height which correlates to the extent of vertebral deformities. The height reduction of patients with COPD was slightly higher than in the control group. Lung function assessed from predicted values of PFTs will be influenced by this height reduction.

\section{Extent of height reduction}

Height reduction was frequent in both the study and control groups. Although height reduction appeared more frequent in the control group, mean height reduction was slightly but significantly larger in the study group. RTH seemed reliably remembered in $97 \%$ of the study group and $92 \%$ of the control group. The fact that RTH and ASHParker were not significantly different strengthens the data on RTH, if ASHParker can be considered a reliable measure of tallest height. Neither RTH nor ASHParker seem optimal as measures of tallest height. RTH could be affected by recall bias, whereas the equation of PARKER et al. [16] yielded erroneous results in a substantial fraction of the subjects. Furthermore, ASH calculated from the equation of PARKER et al. [16] is based on people referred to a pulmonary function laboratory, and we do not know whether they were representative for a general population. Nevertheless, we believe that both RTH and ASHParker can be used as measures of tallest height for clinical purposes. 


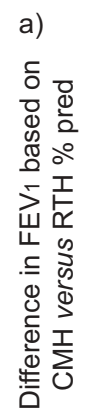

25

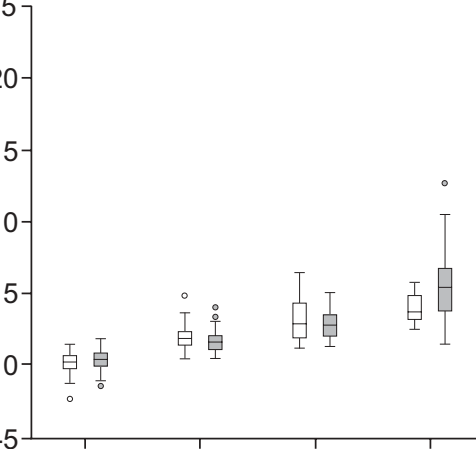

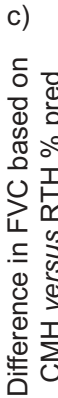

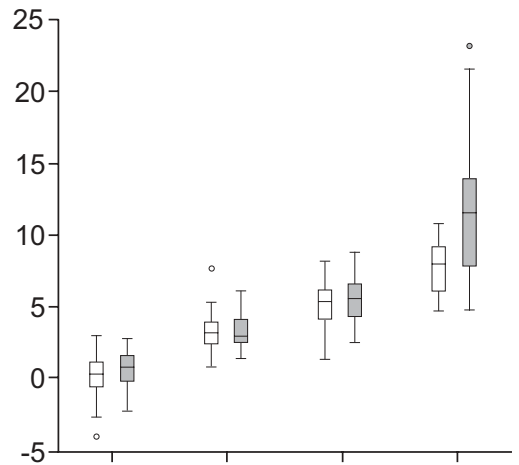

e)
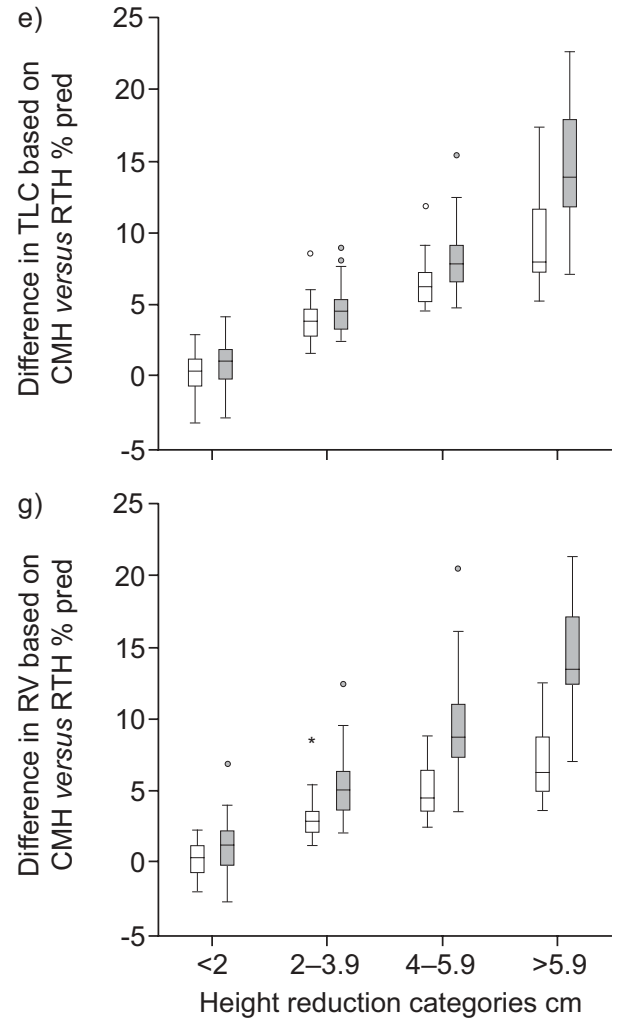
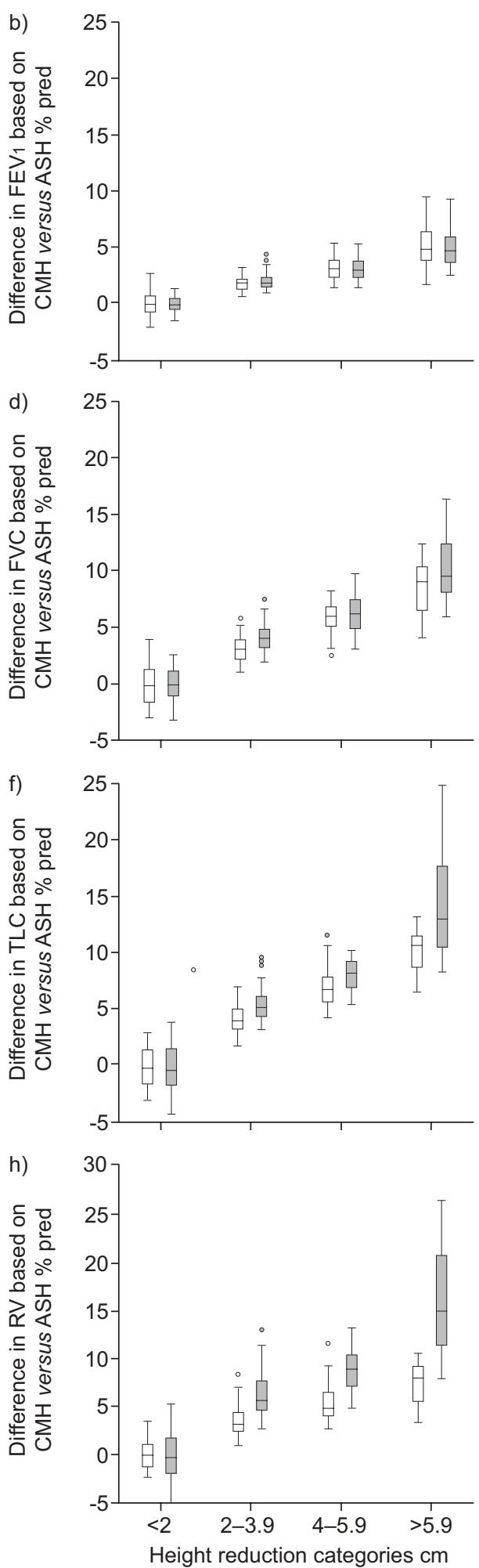

FIGURE 3. Difference in a, b) forced expiratory volume in $1 \mathrm{~s}$ ( $F E V$ 1), c, d) forced vital capacity (FVC), e, f) total lung capacity (TLC) and g, h) residual volume (RV) as \% predicted (\% pred) when calculated from a, c, e, g) current measured height (CMH) versus recalled tallest height (RTH) or b, $d, f, h)$ CMH versus arm span height (ASH) in the different height reduction categories of the study group. $\square$ : males; 1 : females. Prediction equations for FEV1 and FVC are from [12], and for TLC and RV are from [4]. Boxes represent the interquartile range and whiskers represent the range. — : median; $\bigcirc$ : outliers; *: extreme outlier.

The height reduction was significantly correlated with age, as other studies have shown previously [1]. The height reduction was also significantly correlated with height expressed as $(\mathrm{CMH}+\mathrm{RTH}) / 2$, but the change in height reduction with height was negligible and probably not clinically important. No significant sex difference in height reduction was found in either group. 


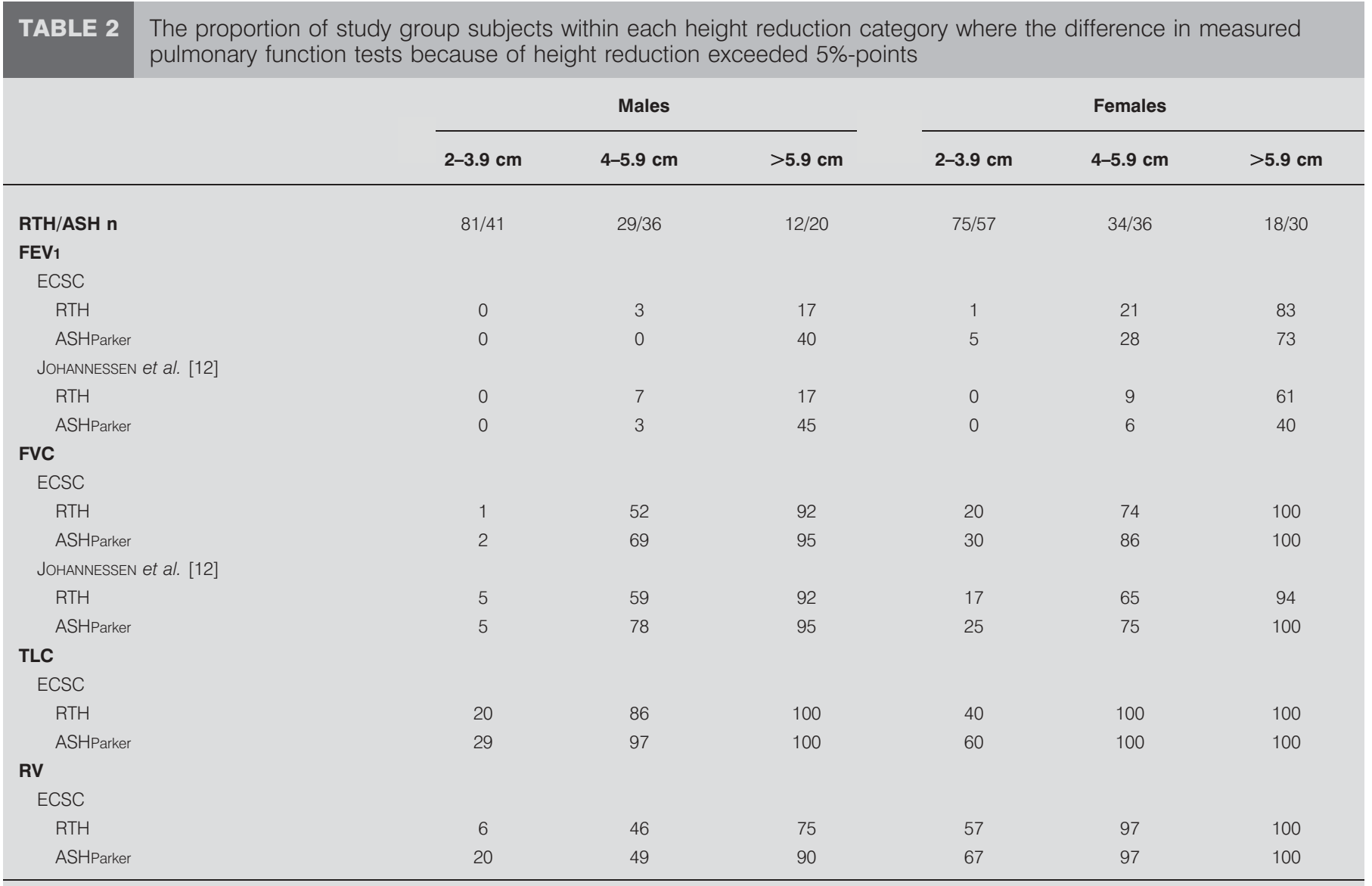

Data are presented as \%, unless otherwise stated. Prediction equations from JoHANNESSEN et al. [12] and European Community for Steel and Coal (ECSC) [4]. FEV1: postbronchodilator forced expiratory volume in $1 \mathrm{~s}$; FVC: post-bronchodilator forced vital capacity; TLC: total lung capacity; RV: residual volume. RTH: prediction equation based on recalled tallest height, ASHParker: prediction equation based on height calculated from arm span using algorithm from PARKER et al. [16].

\section{Consequences for interpretation of lung function}

The effects of height reduction on PFT values relative to predicted were smallest for the indices FEV1 and FVC, and most pronounced for TLC and RV (fig. 3, table 2). The difference in measured FEV1 as \% predicted caused by height reduction exceeded 5\%-points in $21 \%$ of the females with a height reduction of $4-5.9 \mathrm{~cm}$, whereas for RV and TLC a substantial number of the patients exceeded $5 \%$-point difference at height reductions of only $2-3.9 \mathrm{~cm}$ (table 2 ). This difference may be a consequence of the lower than normal values for FEV1 and FVC, and higher than normal values for TLC and RV, in the COPD patients (table 1). Analysis of the ECSC and JOHANNESSEN et al. [12] prediction equations revealed that the height reduction necessary to achieve a $5 \%$-point change in predicted PFT decreases with increasing PFT values. As FEV1 and FVC decrease with advancing COPD, these variables would be expected to become less affected by height reductions than RV and TLC, which increase with advancing disease.

ECSC prediction equations are based on nonsmoking subjects without previous disease which could compromise their ventilatory function [4], and those of JOHANNESSEN et al. [12] were based on healthy never-smokers. Presumably both sets of prediction equations are based on subjects with normal agerelated height reduction.
Reference values for COPD patients with normal age-related height reduction should be based, as normal, on standing height measured according to standard recommendations. For patients with height reductions $\geqslant 4 \mathrm{~cm}$, the PFTs may alternatively be compared to predicted values based on the patient's RTH or ASH. To assess height reduction in the clinic, one would have to either ask about RTH or measure arm span.

We found no significant differences in pulmonary function between subjects with $0,1-2$ or $>2$ vertebral deformities. In contrast, HARRISON et al. [20], reviewing the relationship between vertebral deformities, kyphosis and pulmonary function reported declines in FVC with values ranging from $68 \%$ to $94 \%[6-8,21]$. We think that this difference is explained by the fact that our patients had reduced lung function, whereas HARRISON et al. [20] refers to persons without lung disease. HARRISON et al. [20] concluded that the evidence was limited because of significant methodological limitations. For instance, the studies used different measurements of heights for their PFT reference values.

\section{Height reduction compared to number and severity of vertebral deformities}

Our results demonstrate that increasing height reduction in COPD patients was associated with a larger fraction of subjects 


\begin{tabular}{|c|c|c|c|c|}
\hline \multirow{2}{*}{ TABLE 3} & \multicolumn{3}{|c|}{ Deformities } & \multirow[t]{2}{*}{ p-value } \\
\hline & 0 & $1-2$ & $>2$ & \\
\hline Height reduction from $\mathrm{RTH} \mathrm{cm}$ & $1.8 \pm 1.9$ & $2.8 \pm 2.3$ & $5.1 \pm 3.0$ & $<0.0001$ \\
\hline FVC \% pred & $73 \pm 16$ & $73 \pm 15$ & $67 \pm 13$ & 0.084 \\
\hline TLC \% pred ${ }^{+}$ & $122 \pm 19$ & $119 \pm 23$ & $120 \pm 27$ & 0.365 \\
\hline RV \% pred $^{+}$ & $200 \pm 52$ & $193 \pm 59$ & $199 \pm 65$ & .533 \\
\hline Height reduction from ASHParker $\mathrm{cm}$ & $2.3 \pm 2.7$ & $2.6 \pm 3.0$ & $4.3 \pm 2.8$ & $<0.0001$ \\
\hline RV \% pred $^{+}$ & $210 \pm 51$ & $205 \pm 65$ & $208 \pm 60$ & 0.808 \\
\hline
\end{tabular}

Data are presented as mean \pm SD, unless otherwise stated. FEV1: post-bronchodilator forced expiratory volume in 1 s; FVC: post-bronchodilator forced vital capacity; TLC: total lung capacity; RV: residual volume; \% pred: \% predicted. " $: \mathrm{n}=450$ because TLC and RV were missing in three patients. ": prediction equations from JOHANNESSEN et al. [12]; +: prediction equations from European Community for Steel and Coal [4].

with vertebral deformities, or more deformities, and thus a higher average SDI. An association between height reduction and number of vertebral fractures has previously been described in a general European population [2], and in postmenopausal females with osteoporosis [3]. However, the increase in the total burden of vertebral deformities (SDI) for each height reduction category was higher in the COPD patients than in the control group [2].
The increase in SDI with increasing height reduction was not solely caused by more subjects exhibiting vertebral deformities. It also increased, when only subjects exhibiting vertebral deformities were considered. In these subjects, however, no statistically significant difference in SDI between study and control groups was found. This suggests that deformities were more frequent, but not more severe among the COPD patients.

\section{TABLE 4 Distribution of subjects with deformities and spinal deformity index in each height reduction category based on recalled tallest height}

\begin{tabular}{|c|c|c|c|c|c|}
\hline & \multicolumn{5}{|c|}{ Height reduction category $\mathbf{c m}$} \\
\hline & $<2$ & $2-3.9$ & $4-5.9$ & $>5.9$ & Total \\
\hline \multicolumn{6}{|l|}{ Study group } \\
\hline All subjects ${ }^{\#}$ & $204(45)$ & $156(34)$ & $63(14)$ & $30(7)$ & 453 \\
\hline Subjects with deformities & $43(21)$ & $41(26)$ & $31(49)$ & $21(70)$ & 136 \\
\hline All subjects & $0.41 \pm 0.99$ & $0.93 \pm 2.39$ & $2.24 \pm 4.15$ & $5.41 \pm 5.8$ & $1.18 \pm 2.88$ \\
\hline Subjects with deformities & $1.95 \pm 1.29$ & $3.54 \pm 3.56$ & $4.55 \pm 4.97$ & $7.85 \pm 5.43$ & $3.86 \pm 4.13$ \\
\hline \multicolumn{6}{|l|}{ Control group } \\
\hline All subjects & $164(39)$ & $142(33)$ & $75(18)$ & $44(10)$ & 425 \\
\hline Subjects with deformities & $15(9)$ & $33(23)$ & $18(24)$ & $23(52)$ & 89 \\
\hline No of vertebral deformities & $0.13 \pm 0.47$ & $0.39 \pm 0.86$ & $0.48 \pm 1.38$ & $1.82 \pm 2.71$ & $0.44 \pm 1.25$ \\
\hline
\end{tabular}




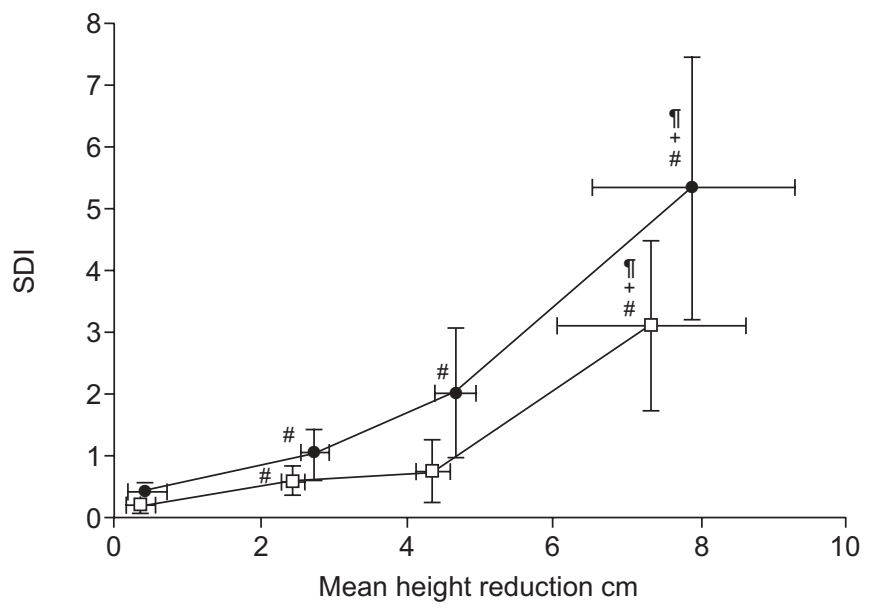

FIGURE 4. Spinal deformity index (SDI) versus height reduction categories based on recalled tallest height. Mean SDI (with 95\% Cl) for chronic obstructive pulmonary disease patients $(\bullet)$ and control group $(\square)$ versus the mean height reduction (with $95 \% \mathrm{Cl}$ ) in the four categories of height reduction $(<2,2-3.9,4-5.9$

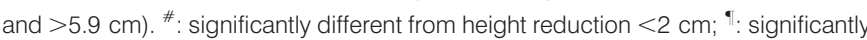
different from height reduction $2-3.9 \mathrm{~cm}$; ${ }^{+}$: significantly different from height reduction $4-5.9 \mathrm{~cm}$.

SIMINOSKI et al. [22] found that a height reduction $\leqslant 6 \mathrm{~cm}$ practically ruled out prevalent vertebral fractures in postmenopausal females. Our control group exhibited significantly increased SDI compared to no height reduction for height reduction $2.0-3.9 \mathrm{~cm}$ and $\geqslant 6 \mathrm{~cm}$, but not for $4.0-5.9 \mathrm{~cm}$. In the COPD patients increased SDI was demonstrated from $2 \mathrm{~cm}$ height reduction.

\section{Strengths and limitations}

The current study has several strengths. All the COPD patients admitted during the study period were evaluated for inclusion. The radiographs from patients and controls were evaluated at a single centre, which excludes between-centre variations in the evaluation of deformities. The height and arm span were measured by trained operators twice within 4 days to reduce day to day variation. Finally, all patients were asked about their RTH in the same way and by the same person.

There are some limitations of the study. Because of the crosssectional design, the RTH-based height reductions could be affected by recall bias. Also, the degree of kyphosis was not assessed. It has previously been shown that hyperkyphosis affects lung function [20] and might also affect the relationship between vertebral deformities and height reduction. Furthermore, subjects in the control group with possible COPD were not excluded since PFTs were not conducted, but the prevalence of COPD in Norway at that time was only 5.4\% [23]. Finally, it should be noted that the height reduction categories of $2 \mathrm{~cm}$ refer to the present study population, and the reproducibility of our height measurements. This might differ for other studies.

\section{Conclusion}

When using $\mathrm{CMH}$, lung function may be overestimated in a large proportion of COPD patients at relatively modest height reductions. Height reduction was frequent in both the study and control groups, and increased with the number and severity of vertebral deformities in both groups.

Pulmonary function tests of COPD patients with a normal agerelated height reduction should be compared to standard reference values based on current measured height. For COPD patients with height reduced more than normal for their age, one might use RTH or ASH in the calculation of predicted values. These patients should be further evaluated for $\mathrm{CO}^{-}$ existing vertebral deformities and the possibility of suffering from osteoporosis.

\section{SUPPORT STATEMENT}

This project has been financed with the aid of funds from the Norwegian Foundation for Health and Rehabilitation, The Norwegian Heart and Lung Patient Organization (LHL), and GlaxoSmithKline via The Norwegian Thoracic Society.

\section{STATEMENT OF INTEREST}

Statements of interest for all authors can be found at www.erj. ersjournals.com $/ \mathrm{misc} /$ statements.dtl

\section{REFERENCES}

1 Sorkin JD, Muller DC, Andres R. Longitudinal change in the heights of men and women: consequential effects on body mass index. Epidemiol Rev 1999; 21: 247-260.

2 Ismail AA, Cooper C, Felsenberg D, et al. Number and type of vertebral deformities: epidemiological characteristics and relation to back pain and height loss. European Vertebral Osteoporosis Study Group. Osteoporos Int 1999; 9: 206-213.

3 Siminoski K, Jiang G, Adachi JD, et al. Accuracy of height loss during prospective monitoring for detection of incident vertebral fractures. Osteoporos Int 2005; 16: 403-410.

4 Quanjer PH, Tammeling GJ, Cotes JE, et al. Lung volumes and forced ventilatory flows. Report Working Party Standardization of Lung Function Tests. European Community For Steel and Coal. Eur Respir J 1993; 6: Suppl. 16, 5-40.

5 Kjensli A, Falch JA, Ryg M, et al. High prevalence of vertebral deformities in COPD patients: relationship to disease severity. Eur Respir J 2009; 33: 1018-1024.

6 Lombardi I Jr, Oliveira LM, Mayer AF, et al. Evaluation of pulmonary function and quality of life in women with osteoporosis. Osteoporos Int 2005; 16: 1247-1253.

7 Schlaich C, Minne HW, Bruckner T, et al. Reduced pulmonary function in patients with spinal osteoporotic fractures. Osteoporos Int 1998; 8: 261-267.

8 Leech JA, Dulberg C, Kellie S, et al. Relationship of lung function to severity of osteoporosis in women. Am Rev Respir Dis 1990; 141: 68-71.

9 Miller MR, Crapo R, Hankinson J, et al. General considerations for lung function testing. Eur Respir J 2005; 26: 153-161.

10 O'Neill TW, Felsenberg D, Varlow J, et al. The prevalence of vertebral deformity in european men and women: The European Vertebral Osteoporosis Study. J Bone Miner Res 1996; 11: 1010-1018.

11 Miller MR, Hankinson J, Brusasco V, et al. Standardisation of spirometry. Eur Respir J 2005; 26: 319-338.

12 Johannessen A, Lehmann S, Omenaas ER, et al. Post-bronchodilator spirometry reference values in adults and implications for disease management. Am J Resp Crit Care Med 2006; 173: 1316-1325.

13 Pellegrino R, Viegi G, Brusasco V, et al. Interpretative strategies for lung function tests. Eur Respir J 2005; 26: 948-968. 
14 Global Initiative for Chronic Obstructive Lung Disease. Global strategy for the diagnosis, management and prevention of COPD. NHLBI/WHO workshop report 2008. www.goldcopd.com/ GuidelineItem.asp? $/ 1=2 \& / 2=1 \&$ int $\mathrm{I}=2003$

15 Linderholm $\mathrm{H}$, Lindgren U. Prediction of spirometric values in patients with scoliosis. Acta Orthop Scand 1978; 49: 469-474.

16 Parker JM, Dillard TA, Phillips YY. Arm span-height relationships in patients referred for spirometry. Am J Resp Crit Care Med 1996; 154: 533-536.

17 Genant $\mathrm{HK}, \mathrm{Wu} \mathrm{CY}$, van KC, et al. Vertebral fracture assessment using a semiquantitative technique. J Bone Miner Res 1993; 8: 1137-1148.

18 Armbrecht G, Blenk T, Chesnut $\mathrm{CH}$ III, et al. Vertebral fracture diagnosis in the multinational BONE study of oral Ibandronate: quality management in radiology. J Clin Densitom 2008; 11: 221-231.
19 Altman DG. Relation Between Two Continuous Variables. Practical Statistics for Medical Research. London, Chapman and Hall, 1999: pp. 293-294.

20 Harrison RA, Siminoski K, Vethanayagam D, et al. Osteoporosisrelated kyphosis and impairments in pulmonary function: a systematic review. J Bone Miner Res 2007; 22: 447-457.

21 Culham EG, Jimenez HAI, King CE. Thoracic kyphosis, rib mobility, and lung volumes in normal women and women with osteoporosis. Spine 1994; 19: 1250-1255.

22 Siminoski K, Warshawski RS, Jen $\mathrm{H}$, et al. The accuracy of historical height loss for the detection of vertebral fractures in postmenopausal women. Osteoporos Int 2006; 17: 290-296.

23 Bakke PS, Baste V, Hanoa R, et al. Prevalence of obstructive lung disease in a general population: relation to occupational title and exposure to some airborne agents. Thorax 1991; 46: 863-780. 